\title{
Pre-slaughter effects on bleed-out times and some behavioural and physiological responses of Nguni and non-descript steers
}

\author{
Y.Z. Njisane \& V. Muchenje ${ }^{\#}$ \\ Department of Livestock and Pasture Science, University of Fort Hare, P. Bag X1314, Alice 5700, South Africa
}

(Received 26 February 2016; Accepted 11 December 2016; First published online 27 December 2016)

\begin{abstract}
Copyright resides with the authors in terms of the Creative Commons Attribution 4.0 South African License.
See: http://creativecommons.org/licenses/by/4.0/za

Condition of use: The user may copy, distribute, transmit and adapt the work, but must recognize the authors and the South African Journal of Animal Science.
\end{abstract}

\begin{abstract}
The effect of loading, transportation, lairage and slaughter conditions on bleed-out times, behavioural and physiological responses of Nguni and non-descript steers reared extensively on natural pastures was investigated. Twenty Nguni (NG) and 20 non-descript (ND) steers were loaded and transported $120 \mathrm{~km}$ from the farm to the abattoir in two groups (TG1 and TG2), each comprised of both genotypes. Some environmental conditions and steer behavioural responses were monitored during on- and off-loading, transportation, lairage, and stunning. Trained observers recorded the posture of the steers during transportation, time-budgets during lairage, avoidance-related behaviour, and vocalization scores at stunning were recorded. The steers were slaughtered in four groups (SG1, SG2, SG3 and SG4) and the number of attempts to stun each steer was recorded. Blood samples were collected from each steer during exsanguination for cortisol, glucose and lactate analysis. It took less time to load (370 s) and off-load (602 s) TG1 than TG2 (420 s and $782 \mathrm{~s}$, respectively). All steers were standing throughout transportation and during the lairage observation period. Avoidance-related behaviour and vocalization in the stunning box were not influenced by genotype. The TG1 steers showed more avoidance behaviour (63.2\%) and higher cortisol $(140.6 \pm 14.50 \mathrm{nmol} / \mathrm{L})$ and lactate $(12.4 \pm 0.83 \mathrm{nmol} / \mathrm{L})$ levels than TG2 $(23.9 \% ; 92.8 \pm 15.38 ; 9.0 \pm 0.88$, respectively). All SG2 steers showed minimal avoidance behaviour with higher cortisol (175.9 \pm 17.24 $\mathrm{nmol} / \mathrm{L})$ and lactate $(13.5 \pm 1.12 \mathrm{mmol} / \mathrm{L})$ levels than other groups. Generally, cortisol and lactate levels were positively correlated $(r=0.70)$. The $5 \%$ vocalization recorded was observed from ND steers, TG1 and SG2. In conclusion, steers of different genotypes displayed similar behavioural and physiological responses to identical pre-slaughter conditions that they were exposed to.
\end{abstract}

Keywords: Cortisol, lactate, lairage duration, on- and off-loading, stun-attempts, transportation

\#Corresponding author: vmuchenje@ufh.ac.za

\section{Introduction}

According to Njisane (2016), Nguni and non-descript beef steers reared extensively in natural pastures spend most of their "free" time between 6:00 and 20:15 feeding (grazing) throughout the different times of the day; with some lying down, standing, walking, drinking water and interacting with one another in between. This is expression of their normal behaviour (Lee et al., 2013). However, they spend more time showing avoidance-related behaviour during management procedures which involve movement from their habitat to handling facilities and human contact, leading to biochemical and/or physiological changes in the animal (Njisane, 2016). These reactions are maximised towards the end of the production cycle, when the pre-slaughter events commence. The removal of slaughter animals from the farm habitat exposes them to various unfamiliar conditions and handling methods at all stages from the farm to the knocking box at the abattoir (Ferguson \& Warner, 2008). Therefore, there is need to pay attention to animal welfare in all stages of production, in order to improve product quality (Chulayo \& Muchenje, 2015).

Steer transportation has been described as the key component joining the events involved in the preslaughter logistics chain (Miranda-de la Lama et al., 2014). Amongst various modes of transportation used for slaughter cattle, road transport is the most significant and economic type which also allows multiple loads of animals in a single trip (Tarrant, 1990). While the processes of loading and off-loading animals were reported to be more stressful than the journey itself (Agnes et al., 1990; Trunkfield \& Broom, 1990), transportation has been recounted to largely induce significant stress in animals being transported (Grandin, 
1997; Warriss, 2000; Maria et al., 2004; Minka \& Ayo, 2007; Ferguson \& Warner, 2008). Furthermore, transportation stress was related to health defects such as respiratory diseases (Sporer et al., 2007; Duff \& Galyean, 2007) and weight losses (Schwartzkopf-Genswein et al., 2012).

Confinement of cattle in a moving vehicle was described as being more stressful compared to confinement in a stationery vehicle, as well as during on and off-loading and re-penning (Tarrant, 1990). However, there is limited information quantifying the effects of loading and off-loading processes on animal welfare (Maria et al., 2004). Jacobson \& Cook (1998) reported that loading is more stressful than off-loading, while Maria et al. (2004) recounted that hurried loading reduced stress metabolites such as cortisol, lactate and creatine phosphokinase. More than anything, the novel conditions to which slaughter animals are exposed prior to slaughter have been generally reported to be stressful and to negatively impact animal welfare (Grandin, 2001; Ekiz et al., 2012; Schwartzkopf-Genswein et al., 2012).

While Grandin (2006) reported that slaughter cattle perceive the abattoir environment in the same way as the farm during managerial procedures, such as moving animals through the race, the abattoir also exposes the animals to a different structural design. Generally, abattoir construction prioritises conventional architectural criteria to maximise operation with less consideration for behavioural characteristics of the animals (Miranda-de la Lama et al., 2010). Similarly, lairage may be characterised by unfamiliar conditions, such as concrete floors as opposed to the natural grassy farm, confinement, multiple abattoir workers, handling procedures, feed restriction, and the presence of unfamiliar animals of different species and from different farms (Hemsworth \& Coleman, 1998; Ferguson \& Warner, 2008; Terlouw \& Porcher, 2005). Furthermore, lairage duration of over 3 hours was reported to be ideal for steers to rest and recover from previous stress caused during transportation (del Campo et al., 2010). However, it was also reported that feed deprivation during this stage may result in alterations in blood stress indicators such as creatine kinase, lactate dehydrogenase, glucose, cortisol and packed cell volume (Ekiz et al., 2012), while longer durations may result in live weight losses through excreting and urinating (Ferguson \& Warner, 2008).

Multiple indicators such as response behaviour towards certain stimuli and the biochemical changes (in the blood, urine, excreta) have been used to quantify animal welfare in different conditions (Muchenje et al., 2009; Gruber et al., 2010; Njisane \& Muchenje, 2013a; Njisane \& Muchenje, 2013b). In addition, avoidance-related behaviour and vocalization have been used to determine animal welfare in abattoirs (Grandin 1998; Manteuffel et al., 2004; Hemsworth et al., 2011; Njisane \& Muchenje, 2013a; Njisane \& Muchenje, 2013b). However, it should be noted that animals of the same species but varying genetically may exhibit differing response-behaviour patterns (Grignard et al., 2001). A possible case may be observed in South Africa, where multiple beef genotypes, such as the indigenous hardy Nguni breed and a large pool of non-descripts/cross-breds, are found in the beef industry. The NG breed has functional characteristics that allow it to perform better than other breeds even during the dry season with poor quality feed (Ndlovu et al., 2009) or during handling at slaughter (Muchenje et al., 2009). The ND genotype, on the other hand, may contain multiple unidentified genes and it comprises 35\% of bulls found in the emerging farming sector (Scholtz et al., 2008). The objective of this study was therefore to investigate the behavioural, bleed-out times and physiological responses of Nguni and non-descript beef steers as affected by on- and off-loading, transportation, lairage and slaughter activities.

\section{Materials and Methods}

All procedures conducted for the purpose of this research were done following and mimicking the worldwide ethical principle considerations to ensure maximum animal welfare. Consent to carry out the study was approved and issued by the University of Fort Hare Ethical Clearance committee (Reference Number: MUC03S1NJI01).

Forty beef steers of two genotypes, Nguni $(n=20)$ and non-descript $(n=20)$, were used in the study. The steers were between 20 - 24 months old, with the last recorded weights at the farm ranging from 202 $360 \mathrm{~kg}$, while $170-310 \mathrm{~kg}$ weights were obtained at the abattoir prior to slaughter. The steers were reared at the University of Fort Hare's Honeydale Research Farm, situated $120 \mathrm{~km}$ inland from the coastline, in the False Thornveld of the Eastern Cape of South Africa. It is located at $32.78^{\circ} \mathrm{S}$ and $26.85^{\circ} \mathrm{E}$, at an altitude of $520 \mathrm{~m}$ above sea level. The topography of the area is generally flat with few slopes. The mean annual temperature of the farm is $18.7^{\circ} \mathrm{C}$. The area receives a low annual rainfall of approximately $480 \mathrm{~mm}$ per annum, both between and within seasons.

The steers were transported to the East London Abattoir (high throughput), which is situated in Cambridge, East London, South Africa. Its geographical coordinates are $32.58^{\circ} \mathrm{S}$ and $27.53^{\circ} \mathrm{E}$. Average midday temperatures in East London range between $20^{\circ} \mathrm{C}$ (July) to $26^{\circ} \mathrm{C}$ (February) with an annual rainfall of about $593 \mathrm{~mm}$ mostly occurring during the summer months. The abattoir operates under typical commercial conditions and is equipped with modern technology to enhance production. It operates according 
to standard laws and regulations governing abattoirs such as "The Meat Act, 2000 and the Animal Protection Act, 1962" to ensure public health safety and good animal welfare.

The steers were scheduled for transportation a day prior to slaughter, allowing them time to rest overnight at the abattoir lairages. They were brought from the farm grazing pastures into the holding pens at least 90 minutes before loading. Prior to loading, the group was randomly divided into two groups of 20 steers for the morning trip (Transport Group 1 - TG1) and another 20 steers for the afternoon trip (Transport Group 2 - TG2). The genotype distribution ratio between the two trips was considered and catered for to ensure that both genotypes were represented in the two trips. In TG1 compartment A were $5 \mathrm{ND}$ and $5 \mathrm{NG}$, with $B$ having $7 \mathrm{ND}$ and $3 \mathrm{NG}$; while TG2 A had $3 \mathrm{ND}$ and $7 \mathrm{NG}$, and $B$ having $5 \mathrm{ND}$ and $5 \mathrm{NG}$ steers. Verbal instructions were used to encourage the steers to move from a $13.5 \mathrm{~m} \times 12.5 \mathrm{~m}$ holding pen into the loading area (5 m long, $1.5 \mathrm{~m}$ high, $4.2 \mathrm{~m}$ wide entrance, $2.3 \mathrm{~m}$ narrow exit), then into the truck. To avoid separation stress, the steers were moved and observed in groups of tens as opposed to individual animal assessment. The variables of interest were: the time it took to load/off-load each group; whether the steers willingly moved or required encouragement to enter/ exit the vehicle; changing direction (opposite) to escape; loss of balance, slipping or falling; and any aggressive behaviour (Mariah et al., 2004; Bourguet et al., 2011; Stockman et al., 2012). The loading and off-loading times of TG1 (370 and 602 seconds, respectively) and TG2 (410 and 782 seconds, respectively) were recorded, respectively. The transportation distance was 250 $\mathrm{m}$ on gravel road within the farm and $120 \mathrm{~km}$ on a tarred road. Traveling time was within two hours in a $2 \mathrm{~m}$ high 2010 Mitsubishi (Model: Fuso FM 16-253) with two compartments of $4 \mathrm{~m} \times 3 \mathrm{~m}$ size and approximately $0.15 \mathrm{~m}$ spacing in-between the side rails. An average speed of $80 \mathrm{~km} / \mathrm{h}$ was used throughout the distance. During transportation, the position and posture (e.g. standing or lying down and direction faced) of animals was observed before leaving the farm and on arrival at the abattoir. All steers in both trips were up on their feet throughout the transportation period, facing various directions as allowed by the conditions. The weather on the day of transportation was cloudy and cool in the morning, with rain in the afternoon.

Upon arrival (both trips) at the abattoir, the steers were kept in the same groups as they were transported and confined into four roofed lairage pens $(5.3 \mathrm{~m} \times 5.3 \mathrm{~m})$. TG1 was lairaged for 20 hours, while TG2 for 15 hours, based on time of transportation and arrival at the abattoir. The steers were fasted during lairage and had ad lib. access to water. In the same surrounding were other cattle from other farms, sheep and squealing pigs. Hourly response behaviour (to the new conditions) observations were monitored by four observers allocated to each group. The records were made during the first 15 minutes of every hour, from the first hour after arrival to 12:15 midnight. TG1 was observed for 12 hours, while TG2 was observed for 7 hours. The behaviours of interest included: standing, lying down, drinking and interactions amongst the steers (e.g. grooming/head butting). Further observations were done between 6:00 and 7:15 of the following day, until the process of regrouping/re-penning began at 8:00 in preparation for slaughter.

The steers were individually weighed $(170-310 \mathrm{~kg}$ range) using a digital alleyway scale before they were moved to the holding pen, then into the stunning box. However, due to the abattoir procedures, no group order was maintained after this process. The study animals were mixed in the holding pen and entered the slaughter alley (leading to the stunning box) randomly, with some vocal assistance encouraging them to move. A manual penetrating captive bolt pistol was used onto each steer's forehead, immediately when it entered the box, to render it unconscious before initializing the exsanguination process within 60 seconds. The whole group of 40 steers was slaughtered within a period of 30 minutes. Records on the number of stuns used per animal to render unconscious, as well as the response behaviour of each steer inside the stunning box, were noted. The behaviour scores recorded in the box were: 0 - Calm, 1 - Head movement up and down avoiding the stunner, 2 - Turning to face the opposite direction, and 3 - Attempts to jump out of the stunning box (Bourguet et al., 2011; Stockman et al., 2012). Further, vocalization was recorded as Yes (score 2) or No (score 1) as adapted from Grandin (1998; 2001). The order of slaughter was also taken note of as the animals entered the slaughter alley and stunning box, with four established Slaughter Groups (i.e. SG1, SG2, SG3, and SG4) of 10 steers per group.

Bleed-out time for each steer was measured by capturing the starting time of the blood flow (exsanguination) and the time the flow changed from a constant stream into drips, using a stop watch; thus recording the difference between the two as the actual time (Kirton \& Woods, 1977). Immediately after initializing the bleeding process, two exsanguination blood samples $(4 \mathrm{~mL}$ each) were collected from each animal into specialized tubes for glucose (grey topped, sodium fluoride tubes), cortisol and lactate (gold/yellow topped serum separator tubes) analysis. The tubes were kept on ice until separation of serum through centrifuging (Gatenbay Eppendorf GmbH, Engelsdorp, Germany; Model 5403 Centrifuge) for 15 min at $10^{\circ} \mathrm{C}$ and $3000 \mathrm{rpm}$. The glucose samples were sent to the laboratory immediately, while the centrifuged serum for cortisol and lactate analysis was transferred into a fresh tube, frozen and then sent to the laboratory for analysis within 5 days of collection, in a foam cooler containing ice packs. Analyses were done at the University of Pretoria Pathology lab for cortisol and lactate, and the National Health Laboratory 
Services, South Africa, for glucose samples. The procedures used to analyse for glucose and cortisol were as described by Chulayo et al. (2016), where glucose was analysed using a classical colorimetric method through an enzymatic kit (Diaglue from L'viv Plant of Bacterial preparation, 1994) and the well-known biosensor analyser, Eksan-G from Panevezhis Plant of precision mechanics, 1990, and cortisol through a competitive assay (LKCO1) (EIA, RADIM, Pomezia, Italy). Lactate was analysed using an enzymatic colorimetric method through a Lactate Colorimetric Assay Kit (COBAS INTEGRA 700 analyzer).

A Chi-square test (SAS, 2003) was used to assess for existing associations between genotype, transport/lairage group and slaughter group with the response behaviour and vocalization scores. Frequencies were calculated using Proc freq procedure of SAS (2003). A PROC GLM test (SAS, 2003) was used to test the effect of genotype, transport/lairage group, slaughter group and the number of stun shots on bleed-out times; and exsanguination blood cortisol, glucose and lactate levels. Differences between means were evaluated using Tukey's test. The model used was:

$$
Y_{i j k l m}=\mu+\alpha_{i}+\beta_{j}+\gamma_{k}+\delta_{l}+e_{i j k l m}
$$

where: $Y_{\mathrm{ijk}}$ is the response variable (bleed-out times, exsanguination blood cortisol, glucose and lactate levels);

$\mu$ is the overall mean,

$\alpha_{i}$ is the genotype effect,

$\beta_{\mathrm{j}}$ is the transport/lairage group effect,

$Y_{k}$ is the slaughter group effect,

$\delta_{l}$ is the effect of the number of stun shots, and

$\mathrm{e}_{\mathrm{ijk} \mathrm{km}}$ is the standard error.

Pearson's correlation coefficients for the relationship between bleed-out times, levels of cortisol, glucose and lactate were also determined (SAS, 2003).

\section{Results}

Records in Table 1 show that the morning group was loaded over a 370 second period, while the afternoon group took 410 seconds to get into the truck. The off-loading times after the journey were longer than the loading times. Transportation Group 1 (TG1) collectively took lesser time to get off than Group 2 (TG2). TG1 spent longer time in the abattoir lairages before slaughter, while Group 2 rested for a shorter period than the former group. The steers were standing and vigilant during the observations in the truck and lairage pens, with minimal movements around the pen.

Table 1 A summary of general observations recorded during loading, off-loading, transportation and lairage

\begin{tabular}{lccccccc}
\hline $\begin{array}{l}\text { Transport } \\
\text { Group }\end{array}$ & $\begin{array}{c}\text { Transport } \\
\text { session }\end{array}$ & $\begin{array}{c}\text { Loading } \\
\text { duration (s) }\end{array}$ & $\begin{array}{c}\text { Weather } \\
\text { conditions }\end{array}$ & $\begin{array}{c}\text { Transport } \\
\text { behaviour }\end{array}$ & $\begin{array}{c}\text { Off-loading } \\
\text { duration (s) }\end{array}$ & $\begin{array}{c}\text { Lairage } \\
\text { duration (h) }\end{array}$ & $\begin{array}{c}\text { Lairage } \\
\text { behaviour }\end{array}$ \\
\hline \multirow{2}{*}{ of 1} & Morning & 205 & Cold \& Cloudy & Standing & 362 & 20 & Standing \\
2 of 1 & Morning & 165 & Cold \& Cloudy & Standing & 240 & 20 & Standing \\
1 of 2 & Afternoon & 180 & Cold \& Rainy & Standing & 362 & 15 & Standing \\
2 of 2 & Afternoon & 240 & Cold \& Rainy & Standing & 420 & 15 & Standing \\
\hline
\end{tabular}

All the steers of both genotypes showed some kind of avoidance behaviour inside the stunning box, none of them was calm. However, both avoidance-related behaviour $(x 2=0.0715)$ and vocalization $(x 2=$ 0.3112 ) did not differ with genotype (Figures $1 \mathrm{a}$ and $1 \mathrm{~b}$ ). Over $50 \%$ of the steers of both genotypes were moving their head either up and/or down in trying to avoid the gun stunner pointed to their heads. Some of the steers even turned to face the opposite direction they came from; while some attempted to jump out of the stunning box. Furthermore, $5 \%$ of ND steers vocalized while the rest, including all the NG steers, did not vocalize. 


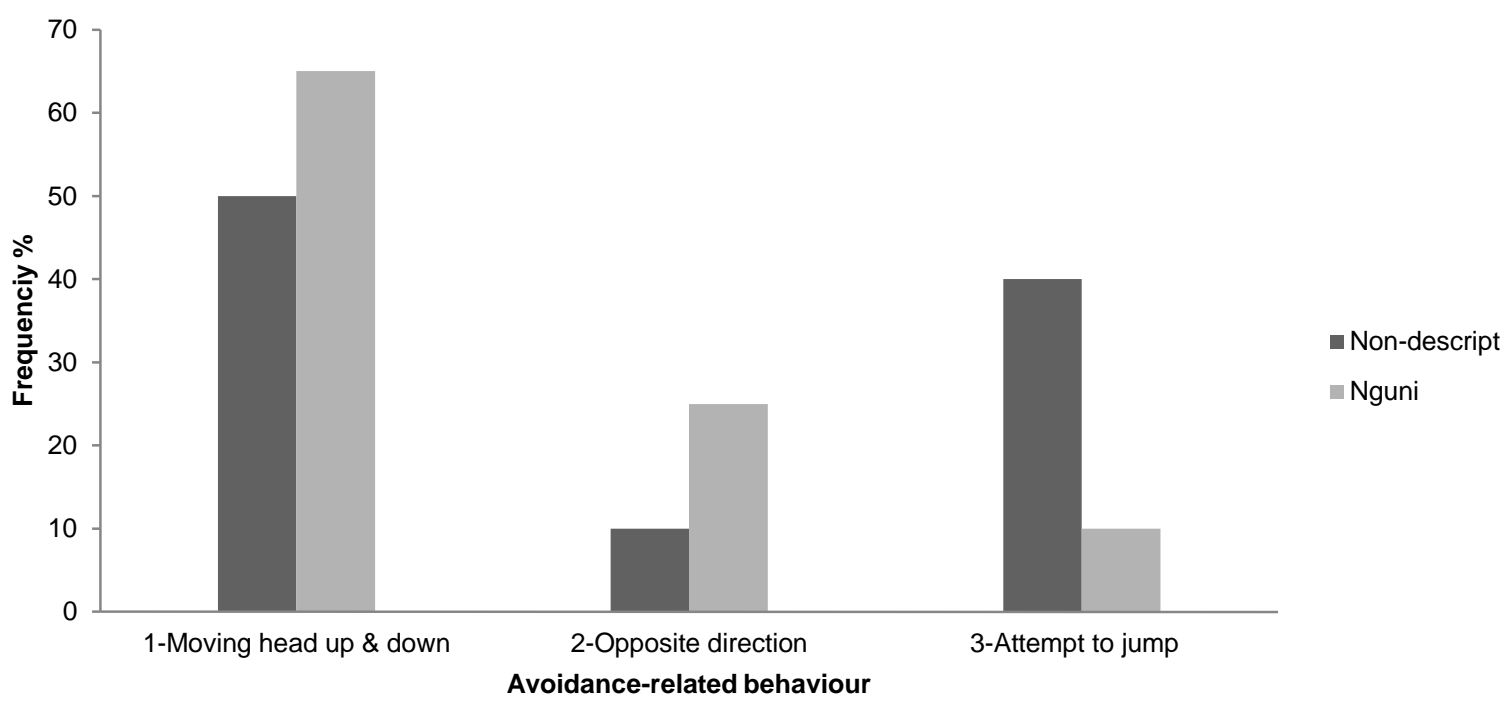

$1 a$

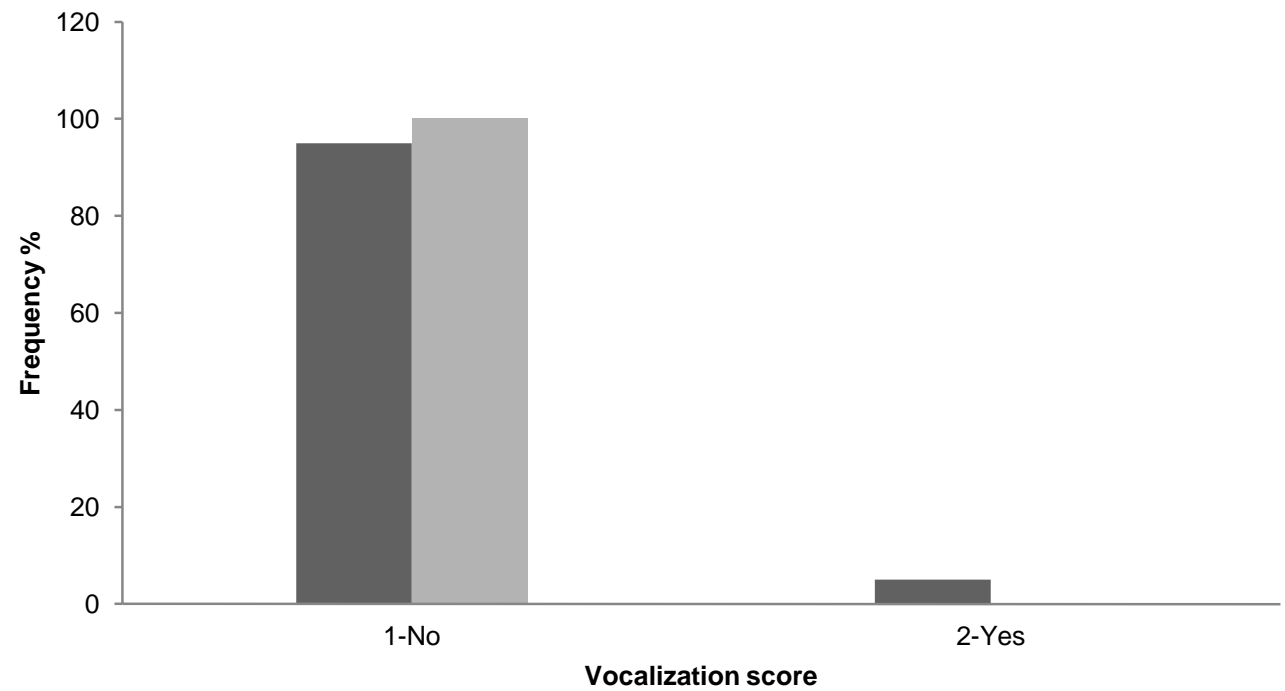

- Non-descript

$\varpi$ Nguni

$1 \mathrm{~b}$

Figure 1 Frequencies of avoidance-related behaviour (a) and vocalization (b) by the two genotypes in the stunning box.

The avoidance-related behaviour (Figure 2a) was influenced by transportation group ( $x 2=0.0246$ ) while vocalization (Figure $2 b$ ) was not $(x 2=0.2870)$. About $36.8 \%$ of steers that were transported in the first trip and lairaged for longer were moving their head up and/or down, while a larger proportion $(76.2 \%)$ of steers that showed this behaviour were transported in the second trip and lairaged for a shorter period. However, $31.6 \%$ of the Group 1 steers turned to face the opposite direction with another $31.6 \%$ even attempting to jump out of the stunning box; while only a few of the Group 2 steers behaved as such, respectively. Furthermore, the only steers that were vocal belonged to Group 1. 


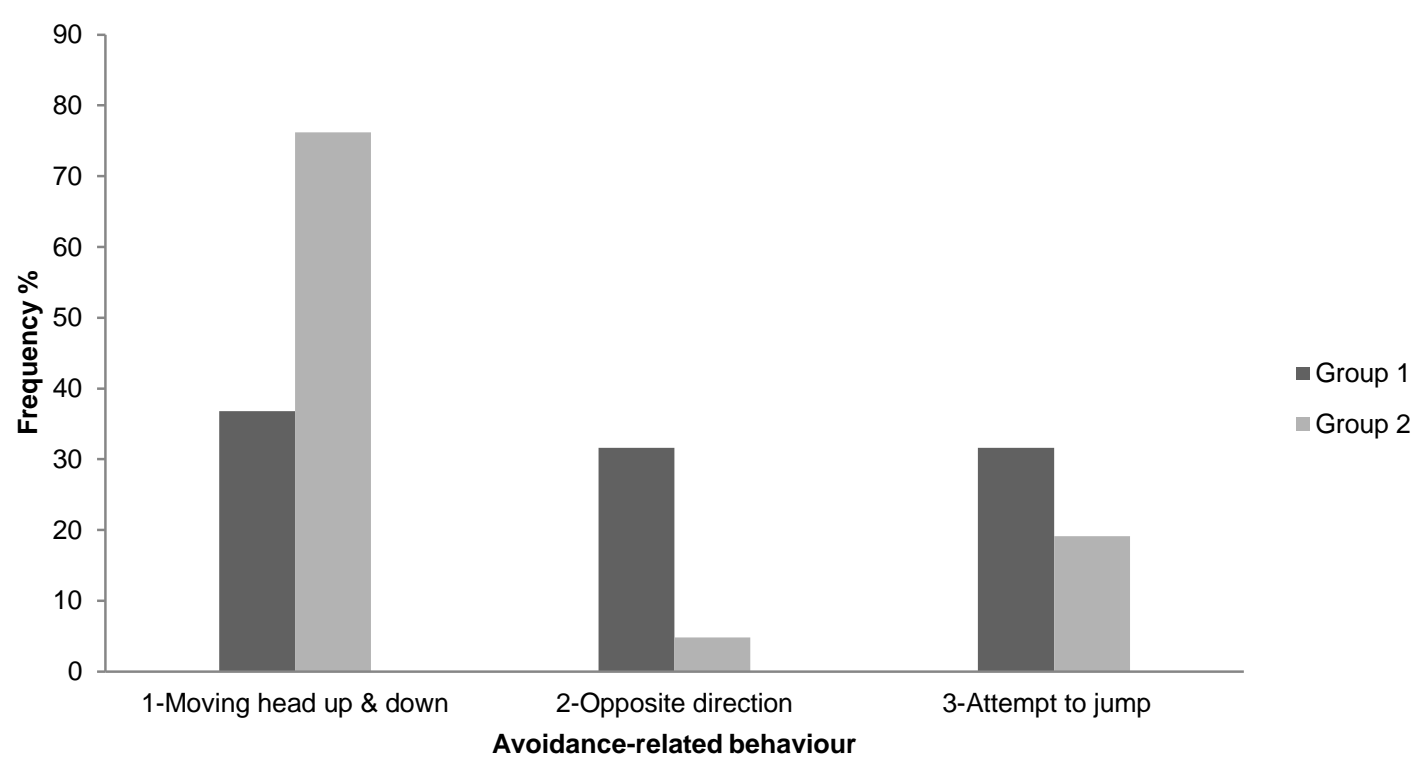

$2 a$

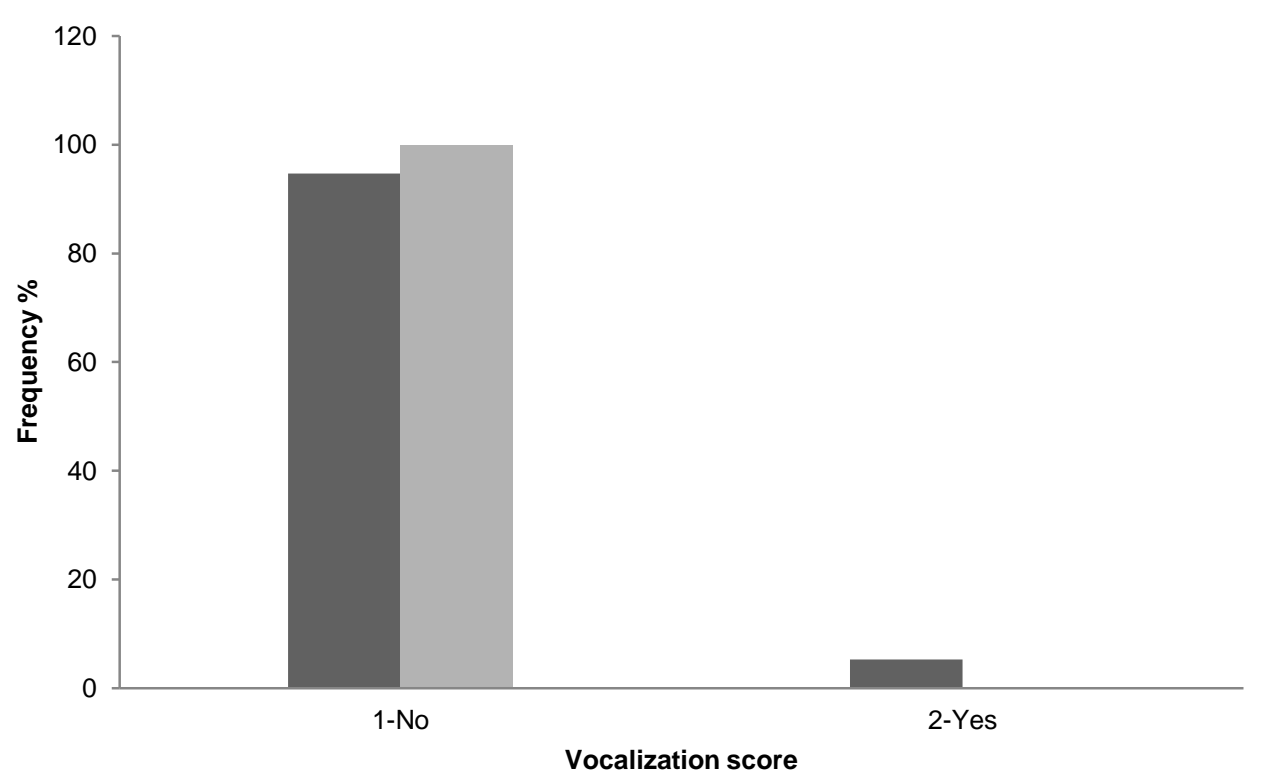

- Group 1

- Group 2

$2 b$

Figure 2 Frequencies of avoidance-related behaviour (a) and vocalization (b) in the stunning box by the two successive groups transported and lairaged.

The avoidance-related behaviour (Figure $3 a)$ was influenced by slaughter group $(x 2=0.0445)$, while vocalization (Figure $3 b)$ was not $(X 2=0.3799)$. Half of the steers slaughtered in the first group (SG 1$)$ were moving their heads up and/or down avoiding the stunner; while some of the total SG1 steers turned to face the opposite direction and others even attempted to jump out of the stunning box. From Group 2 (SG2), 30\% head movements, $30 \%$ turned to the opposite direction and $40 \%$ tried to jump out were recorded. All the steers that were in Group 3 only moved their heads, avoiding the stunner. Only half of the last group (Group 4) showed head avoidance, with $10 \%$ facing the opposite direction and $40 \%$ trying to jump out of the stunning box. Vocalization was only recorded in Group 2, while the rest in other groups did not vocalize at all. 


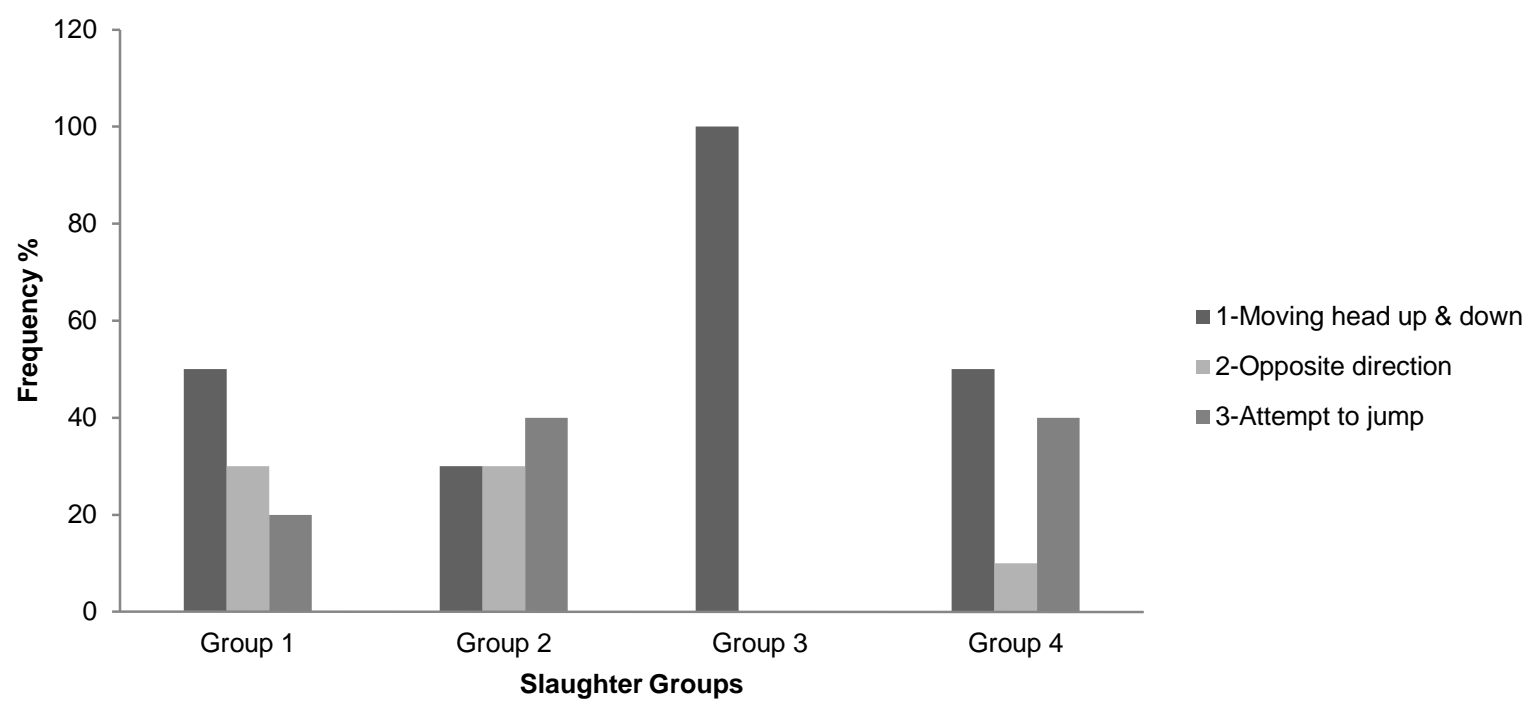

$3 a$

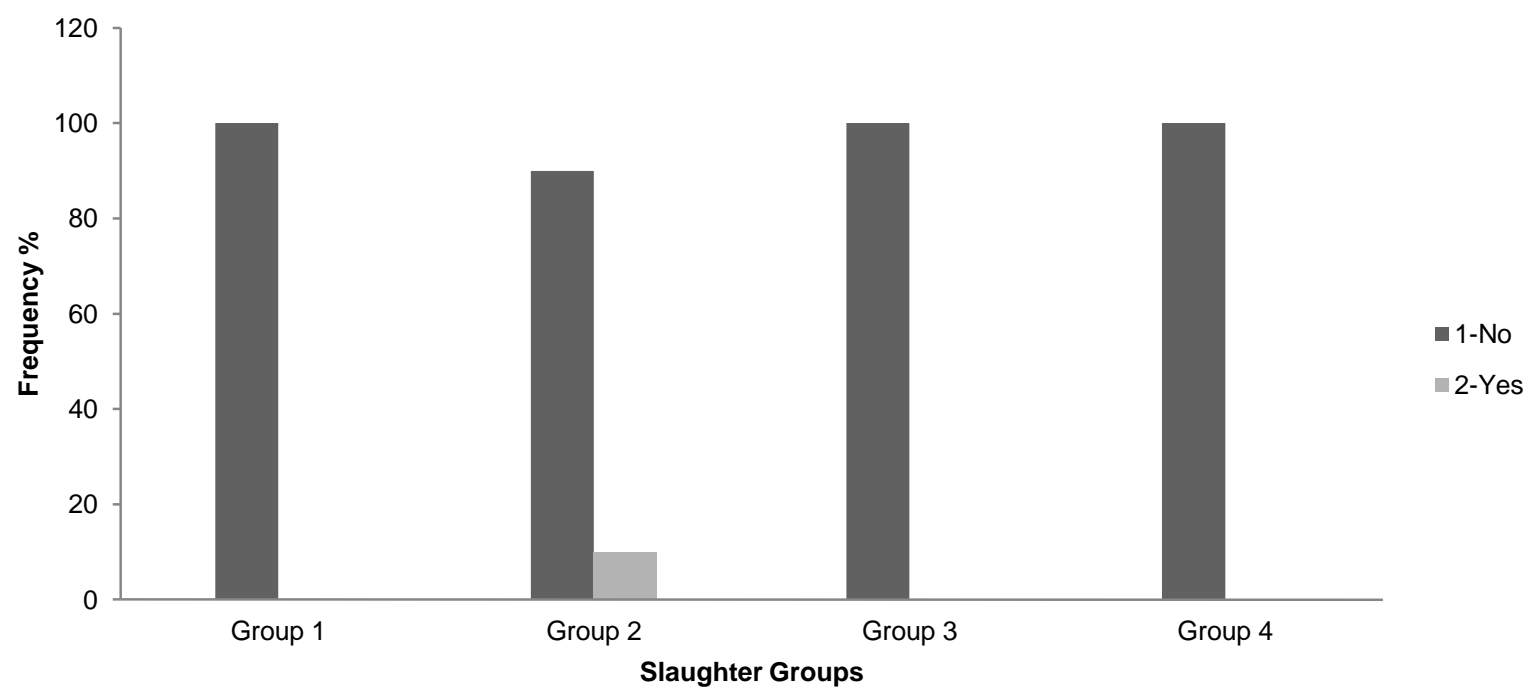

$3 b$

Figure 3 Frequencies of avoidance-related behaviour ( $3 a)$ and vocalization ( $3 b)$ in the stunning box by the four successive groups of slaughter

Genotype had no effect on bleed-out times $(P=0.9787)$, cortisol $(P=0.7940)$, glucose $(P=0.1556)$ and lactate $(P=0.7659)$ levels. Both ND and NG steers on average took $76 \pm 7.90$ seconds to bleed-out. The average serum cortisol levels were $114.5 \pm 16.55 \mathrm{nmol} / \mathrm{L}$ (ND) and $120.9 \pm 15.60 \mathrm{nmol} / \mathrm{L}$ (NG). Similarly, the $\mathrm{ND}$ steers had $5.3 \pm 0.40 \mathrm{mmol} / \mathrm{L}$ glucose and $10.6 \pm 0.98 \mathrm{mmol} / \mathrm{L}$ lactate, while the NG steers had $6.2 \pm$ $0.38 \mathrm{mmol} / \mathrm{L}$ glucose and $11.0 \pm 0.93 \mathrm{mmlo} / \mathrm{L}$ lactate levels.

Furthermore, the bleed-out times $(P=0.7191)$ and glucose $(P=0.1523)$ levels did not differ with transportation group and lairage time. However, Table 2 shows that cortisol $(P=0.0307)$ and lactate $(P$ $=0.0069)$ were affected by transportation group and lairage time. Cortisol levels were higher for steers in Group 1 than those in Group 2. Similarly, the lactate levels were higher for steers in Group 1 than those in Group 2. 
Table 2 Mean $( \pm \mathrm{SE})$ transportation and lairage grouping on bleed-out times (s) and the levels of cortisol $(\mathrm{nmol} / \mathrm{L})$, glucose $(\mathrm{mmol} / \mathrm{L})$ and lactate $(\mathrm{mmol} / \mathrm{L})$ from exsanguination blood

\begin{tabular}{lccc}
\hline Variables & Group 1 & Group 2 & $P$-value \\
\hline Bleed-out times (s) & $73.5 \pm 8.09$ & $77.6 \pm 7.69$ & 0.7191 \\
Cortisol (nmol/L) & $140.6^{\mathrm{a}} \pm 14.50$ & $92.8^{\mathrm{b}} \pm 15.38$ & $0.0307^{\star}$ \\
Glucose (mmol/L) & $5.4 \pm 0.38$ & $6.2 \pm 0.40$ & 0.1523 \\
Lactate (mmol/L) & $12.4^{\mathrm{a}} \pm 0.83$ & $9.0^{\mathrm{b}} \pm 0.88$ & $0.0069^{\star}$ \\
\hline
\end{tabular}

${ }^{\text {a, }}$ Row Means with different superscripts differ significantly at $P<0.05$.

Similarly, the bleed-out times $(P=0.7755)$ and glucose $(P=0.0827)$ levels did not differ with slaughter group. However, Table 3 shows that cortisol $(P=0.0031)$ and lactate $(P=0.0408)$ levels were affected by slaughter group. Cortisol levels were higher for steers in Group 1, followed by Groups 3 and 4, and then Group 2 had the lowest levels. Additionally, the lactate levels were higher for steers in Groups 1 and 3, then Groups 2 and $4(8.7 \mathrm{mmol} / \mathrm{L})$.

Table 3 Mean ( \pm SE) slaughter grouping on bleed-out times (s) and the levels of cortisol (nmol/L), glucose $(\mathrm{mmol} / \mathrm{L})$ and lactate $(\mathrm{mmol} / \mathrm{L})$ from exsanguination blood

\begin{tabular}{lccccc}
\hline Variables & Group 1 & Group 2 & Group 3 & Group 4 & $P$-value \\
\hline Bleed-out times (s) & $71.7 \pm 11.30$ & $85.5 \pm 11.30$ & $70.3 \pm 11.30$ & $75.1 \pm 11.30$ & 0.7755 \\
Cortisol (nmol/L) & $175.9^{\mathrm{a}} \pm 17.24$ & $83.3^{\mathrm{c}} \pm 17.24$ & $91.2^{\mathrm{b}} \pm 19.28$ & $115.8^{\mathrm{b}} \pm 22.26$ & $0.0031^{*}$ \\
Glucose (mmol/L) & $5.1 \pm 0.47$ & $5.3 \pm 0.50$ & $6.8 \pm 0.56$ & $6.5 \pm 0.61$ & 0.0827 \\
Lactate (mmol/L) & $13.5^{\mathrm{a}} \pm 1.12$ & $9.6^{\mathrm{b}} \pm 1.12$ & $10.5^{\mathrm{ab}} \pm 1.26$ & $8.7^{\mathrm{b}} \pm 1.45$ & $0.0408^{*}$ \\
\hline
\end{tabular}

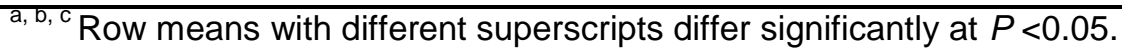

The number of attempts to stun each steer had no significant effect on bleed-out times $(P=0.1185)$ and the levels of serum cortisol $(P=0.2627)$, glucose $(P=0.5743)$, and lactate $(P=0.2243)$. However, though it was not statistically significant, the steers that were successfully stunned on first attempt bled longer (79.9 $\pm 5.71 \mathrm{~s})$ than the 2 nd $(45.0 \pm 19.51 \mathrm{~s})$ and $3 \mathrm{rd}(46.5 \pm 23.89 \mathrm{~s})$ attempts, and had the lowest cortisol levels $(112.1 \pm 11.77 \mathrm{nmol} / \mathrm{L})$ compared to the other two groups (2 attempts $=149.6 \pm 37.23 \mathrm{nmol} / \mathrm{L}$ and 3 attempts $=205.0 \pm 64.48 \mathrm{nmol} / \mathrm{L})$. Similarly, the former group had the lowest serum lactate levels $(10.5 \pm 0.70$ $\mathrm{mmol} / \mathrm{L})$ compared to the 2nd $(11.8 \pm 2.20 \mathrm{mmol} / \mathrm{L})$ and $3 \mathrm{rd}(17.1 \pm 3.81 \mathrm{mmol} / \mathrm{L})$ attempts. Lastly, the blood glucose levels were more similar with 1st attempt value being $5.8 \pm 0.30 \mathrm{mmol} / \mathrm{L}$, 2nd attempt at $6.4 \pm 0.93$ $\mathrm{mmol} / \mathrm{L}$ and $3 \mathrm{rd}$ attempt at $4.5 \pm 1.61 \mathrm{mmol} / \mathrm{L}$.

There were no significant relationships between the bleed-out times, cortisol, glucose and lactate levels. However, there was an overall positive correlation $(r=0.70$ at $P<0.0001)$ found between cortisol and lactate levels at the abattoir. This relationship was also observed from the results obtained at the farm throughout the trial; week $1(r=0.49$ at $P=0.0038)$, week $2(r=0.32$ at $P=0.0507)$, week $3(r=0.41$ at $P$ $=0.0122)$, week $4(\mathrm{r}=0.62$ at $P<0.0001)$, week $5(\mathrm{r}=0.49$ at $P=0.0021)$, week $6(\mathrm{r}=0.34$ at $P=0.0424)$, week $7(r=0.39$ at $P=0.0157)$, and week $8(r=0.47$ at $P=0.0024)$. In addition, cortisol levels obtained at the abattoir (week 9) positively correlated to week $3(r=0.36$ at $P=0.0444)$ at the farm; while lactate level obtained in week 9 positively correlated with week $3(r=0.41$ at $P=0.0240)$ and week $5(r=0.35$ at $P$ $=0.0515$ ) at the farm. Glucose levels from the abattoir did not relate with any levels measured at the farm.

\section{Discussion}

The similar response behaviour and physiological changes between the two genotypes may be attributed to the fact that the steers used, were introduced to the same treatment and conditions at an early age and at the same time. They had been reared together as one group at the farm from the beginning of the trial until slaughter. These results concur with those reported by Probst et al. (2014) that there were no breed effects on any of the stress-indicating traits they measured. This can also be attributed to the fact that cattle 
are herd animals, showing more group behaviour than individual (Grandin \& Deesing, 2014). A similar pattern was also seen in two preceding experiments on the same animals in which no breed effects were identified during handling behaviour and blood analysis at the farm or on the time-budgets of these steers (Njisane, 2016). In addition, the steers' standing position throughout transportation may be related to the short distance travelled to the abattoir $(120 \mathrm{~km})$, while their standing in lairages may have been due to discomfort in a new exposure with concrete and wet floors (caused by rain). Seshoka et al. (2013) reported an increase in salivary cortisol level during shorter distances travelled than longer.

Though not statistically significant in the current study, ND steers exhibited more avoidance behaviour than the NG steers. Some similar results were also obtained in an earlier study (Njisane, 2016). In addition, the recorded vocalization was from the ND steers. Cross-bred cattle have been reported to have high excitability and to be hard to handle, compared to pure bred (Grandin, 1989), and are thus susceptible to stress. In addition, Grandin (2001) reported that vocalization is associated with aversive and physiological measures of stress. Furthermore, the non-significant effect of genotype on the bleed-out times and the exsanguination serum levels of cortisol, glucose, and lactate confirm the results obtained on the behavioural observations. Increased levels of cortisol, glucose and lactate are expected to reflect stress-related behaviour and excessive muscle activity (Shaw \& Tume, 1992; Gruber et al., 2010; Leroy et al., 2011). In addition, the relationship observed between abattoir cortisol and lactate levels together with weeks 3 and 5 at the farm agrees with the fact that metabolites reflect stress-related behaviour (Njisane, 2016).

Although it took a shorter time to load and off-load, TG1 showed more signs of stress than TG2 (Figure 2 and Table 2). This is in contrast with reports that quick loading minimises stress (Maria et al., 2004). In addition, it was reported that loading animals onto the vehicle takes longer and is more stressful than off-loading (Maria et al., 2004). The opposite was recorded for the current study, where longer periods were required for off-loading than on-loading. Furthermore, the increased avoidance-related behaviour, as well as the levels of serum cortisol and lactate exhibited by the steers that were transported in the morning (Group 1) and thus lairaged and rested longer at the abattoir, was not entirely expected. However, Gruber et al. (2010) reported that elevated levels of lactate indicate stress-related behaviour at the abattoir.

The current findings are in contrast with reports that longer resting hours before slaughter improve animal welfare thus better response during slaughter. del Campo et al. (2010) reported that resting duration of over three hours promotes recovery from the transportation stress. In addition, animals are expected to acclimatize to a specific condition after some time of exposure. However, these expectations may be in contrast with what actually happens due to the fact that the abattoir still provides a novel environment to the animals, which may even be enhanced by varying procedures (i.e. frequent handling, concrete floors, food deprivation and noise) from point of arrival through to slaughter, regardless of the resting allowance. Therefore, elongating the time may exert even more stress to the animals. In addition, a study by Probst et al. (2014) reported 26 seconds to be the average time spent by the animals in the stunning box and it was further reported that higher cortisol levels were detected in cattle that spent longer times inside the box.

The steers that were in the front and the end of the slaughter line showed varying response behaviour, with more avoidance, and this phenomenon is not clearly understood. However, it could be attributed to being the first ones in their group to enter the dark alley and the others in the group being left behind with their herd-mates disappearing. Furthermore, Group 3 showed less avoidance-related behaviour and this was attributed to that they had seen more of their herd-mates going into the slaughter alley. Grandin \& Deesing (2014) described cattle as herd animals; they prefer moving in their usual groups. However, an increase in avoidance behaviour was seen again in the last group. Similarly, SG1 had the highest cortisol and lactate levels compared to the rest of the groups. Stewart et al. (2015) reported that "kill-order" may better reflect acute stress, with successive order showing higher pre-slaughter stress indicators.

In addition, Grandin (2006) reported that the animals are not aware that they will die at the abattoir. Furthermore, the number of attempts to stun each animal may have been found to have no influence on bleed-out times and the blood metabolites. However, reports have been made that the stunning process influences bleeding (Lawrie \& Ledward, 2006; Agbeniga \& Webb, 2012). Sheep and cattle that were stunned using the captive-bolt method had a higher blood yield than those that were not stunned (Anil et al., 2004; 2006). Therefore, minimal bleeding may be associated with stress. However, the number of stun attempts did not seem to influence any of the measured stress indicators. In addition, samples that measured higher cortisol correspondingly showed elevated lactate levels as well. The current results are in agreement with the reports on the subsequent relationship of the two metabolites (Shaw \& Tume, 1992; Gruber et al., 2010; Leroy et al., 2011). This relationship was observed throughout the trial.

\section{Conclusion}

Steers of the two genotypes, reared together under the same conditions, responded similarly to identical pre-slaughter conditions they were exposed to. Avoidance-related behaviour, serum cortisol and 
lactate levels only changed according to transportation/lairage groups and slaughter groups. The steers that were transported in the morning, thus rested longer in the lairages, were similarly distributed across the avoidance behaviour scores at slaughter with higher cortisol and lactate levels, while the second group was less avoiding. Those that were in the first slaughter group also had higher cortisol and lactate levels compared to other groups; while different levels of avoidance-related behaviours were seen in some steers of SG 1, 2 and 4. Generally, a positive correlation exists between cortisol and lactate levels. There is a connection between pre-slaughter activities and the behavioural and physiological changes of slaughter steers. Further research is required to determine the qualitative and quantitative effects of these variables on the quality of meat produced.

\section{Acknowledgements}

The authors would like to thank the National Research Foundation (NRF): Innovation Doctoral Scholarship (Grant UID: 86113), DAFF/RTF (Reference: RTF14013163029) and Red Meat Research and Development of South Africa (RMRDSA- Authorization number: IT8114/98) for funding this research.

\section{Authors' Contribution}

YZN is the principal author and the main writer of the manuscript; she also designed and executed the study. VM is the second and corresponding author of the manuscript. He is also the project leader and a grant holder; he designed the main project and supervised YZN. Finally, he contributed in commenting on the manuscript before it was submitted for publication consideration.

\section{Conflict of Interest Declaration}

The authors declare that they have no affiliations with any organisation or entity with any financial or non-financial interest that could bias the subject matter and outcomes discussed in this manuscript.

\section{References}

Agbeniga, B. \& Webb, E.C., 2012. Effect of slaughter technique on bleed-out, blood in the trachea and blood splash in the lungs of cattle. S. Afr. J. Anim. Sci. 42, 524-529.

Agnes, F., Sartorelli, P., Abdi, B.H. \& Locatelli, A., 1990. Effect of transport loading or noise on blood biochemical variables in calves. Am. J. Vet. Res. 51, 1679-1681.

Anil, M.H., Yesildere, T., Aksu, H., Matur, E., Mckinstry, J.L., Erdogan, O., Hughes, S. \& Mason, C., 2004. Comparison of religious slaughter of sheep with methods that include pre-slaughter stunning, and lack of exsanguination, packed cell volume and meat quality parameters. Anim. Welfare 13, 387-392.

Anil M.H., Yesildere T., Aksu H., Matur E., Mckinstry J.L., Erdogan, O., Hughes S. \& Mason C., 2006. Comparison of Halaal slaughter with aptive bolt stunning and neck cutting in cattle; exsanguination and quality parameters. Anim. Welfare 15, 325-330.

Animals Protection Act 1962. Act No. 71 of 1962. http://www.daff.gov.za/doaDev/sideMenu/acts/11\%20Animal\%20Protection\%20No71\%20(1962).pdf (Accessed August 2013).

Bourguet, C., Deiss, V., Tannugi, C.C. \& Terlouw. E.M.C., 2011. Behavioural and physiological reactions of cattle in a commercial abattoir: Relationships with organisational aspects of the abattoir and animal characteristics. Meat Sci. 88, 158-168.

Chulayo, A.Y. \& Muchenje, V. 2015. A balanced perspective on animal welfare for improved meat and meat products. S. Afr. J. Anim. Sci. 45, 452-469.

Chulayo, A.Y., Bradley, G. \& Muchenje, V. 2016. Effects of transport distance, lairage time and stunning efficiency on cortisol, glucose, HSPA1A and how they relate with meat quality in cattle. Meat Sci. 117, 89-96.

del Campo, M., Brito, G., Soares de Lima, J., Hernández, P. \& Montossi, F., 2010. Finishing diet, temperament and lairage time effects on carcass and meat quality traits in steers. Meat Sci. 86, 908-914.

Duff, G.C. \& Galyean, M.L., 2007. Board invited review: recent advances in management of highly stressed, newly received feedlot cattle. J. Anim. Sci. 85, 823-840.

Ekiz, E., Ekiz, E.E., Kocak, O., Yalcintan, H. \& Yilmaz, A., 2012. Effect of pre-slaughter management regarding transportation and time in lairage on certain stress parameters, carcass and meat quality characteristics in Kivircik lambs. Meat Sci. 90, 967-976.

Ferguson, D.M. \& Warner, R.D., 2008. Have we underestimated the impact of pre-slaughter stress on meat in ruminants? Meat Sci. 80, 12-19.

Grandin, T. \& Deesing, M.J., 2014. Genetics and behaviour during handling, restraint, and herding. In: Genetics and the Behaviour of Domestic Animals II. pp.115-158 (Abstract).

Grandin, T., 1989. Behavioural Principles of Livestock Handling (With 1999, 2002, 2010, 2014, and 2015 Updates on Vision, Hearing, and Handling Methods in Cattle and Pigs). Reviewed by S.D. Musgrave and G.W. Thrasher. American Registry of Professional Animal Scientists, pp 1-11.

Grandin, T., 1997. Assessment of stress during handling and transport. J. Anim. Sci. 75, 249-257.

Grandin, T., 1998. The feasibility of using vocalization scoring as an indicator of poor welfare during cattle slaughter. Appl. Anim. Behav. Sci. 56, 121-128. 
Grandin, T., 2001. Cattle vocalizations are associated with handling and equipment problems in beef slaughter plants. Appl. Anim. Behav. Sci. 2, 191-201.

Grandin, T., 2006. Progress and challenges in animal handling and slaughter in the U.S.: Sentience in animals. Appl. Anim. Behav. Sci. 100, 129-139.

Grignard, L., Boivin, X., Boissy, A. \& Le Neindre, P. 2001. Do beef cattle react consistently to different handling situations? Appl. Anim. Behav. Sci. 71, 263-276.

Gruber, S.L., Tatum, J.D., Engle, T.E., Chapman, P.L., Belk K.E. \& Smith. G.C., 2010. Relationships of behavioural and physiological symptoms of pre-slaughter stress to beef longissimus muscle tenderness. J. Anim. Sci. 88, 11481159.

Hemsworth, P.H. \& Coleman. G.J., 1998. Human-Livestock interactions. In: The stockperson and the productivity of intensively farmed animals. Wallingford: $C A B$ International.

Hemsworth, P.H., Rice, M., Karlen, M.G., Calleja, L., Barnett, J.L., Nash J. \& Coleman, G.J., 2011. Human-animal interactions at abattoirs: Relationships between handling and animal stress in sheep and cattle. Appl. Anim. Behav. Sci. 135, 24-33.

Jacobson, L.H. \& Cook, C.J., 1998. Partitioning psychological and physical sources of transport related to stress in young cattle. Vet. J. 155, 205-208.

Kirton, A.H. \& Woods, E.G., 1977. Blood weights, bleeding times of electrically stunned sheep slaughtered by three different methods. New Zeal. J. Agr. Res. 20, 441-451.

Lawrie R.D. \& Ledward D.A., 2006. Lawrie's Meat Science. Seventh edition. Woodhead Publications, Cambridge, England.

Lee, C., Fisher, A.D., Colditz, I.G., Lea, J.M. \& Ferguson, D.M. 2013. Preference of beef cattle for feedlot or pasture environments. Appl. Anim. Behav. Sci. 145, 53-59.

Leroy, J.L.M.R., Bossaert, P., Opsomer, G. \& Bols, P.E.J., 2011. The effect of animal handling procedures on the blood non-esterified fatty acid and glucose concentrations of lactating dairy cows. Vet. J. 187, 81-84.

Manteuffel, G., Puppe, B. \& Schon, P.C., 2004. Vocalization of farm animals as a measure of welfare. Appl. Anim. Behav. Sci. 88, 163:182.

Maria, G.A., Villarroel, M., Chacon, G. \& Gebresenbet, G., 2004. Scoring system for evaluating the stress to cattle of commercial loading and unloading. Vet. Rec. 154, 818-821.

Meat Safety Act 2000. Act No. 40 of 2000. http://www.daff.gov.za/doaDev/sideMenu/acts/21\%20Meat\%20Safety\%20No40\%20(2000).pdf (Accessed August 2013).

Minka, N.S. \& Ayo, J.O., 2007. Physiological responses of transported goats treated with ascorbic acid during the hot-dry season. Anim. Sci. J. 78, 164-172.

Miranda-de la Lama, G.C., Villarroel, M. \& María, G.A. 2014. Livestock transport from the perspective of the preslaughter logistic chain: A review. Meat Sci 98, 9-20.

Miranda-de la Lama, G.C., Villarroel, M., Liste, G., Escosa, J. \& María, G.A., 2010. Critical points in the pre-slaughter logistic chain of lambs in Spain that may compromise the animal's welfare. Small Rumin. Res. 90, 174-178.

Muchenje, V., Dzama, K., Chimonyo, M., Strydom, P.E. \& Raats, J.G., 2009. Relationship between pre-slaughter stress responsive and beef quality in three cattle breeds. Meat Sci. 81, 653-657.

Ndlovu, T., Chimonyo, M., Okoh, A.I., Muchenje, V., Dzama, K., Dube, S. \& Raats, J.G. 2009. A comparison of nutritionally-related blood metabolites among Nguni, Bonsmara and Angus steers raised on sweetveld. The Vet. J. 179, 273-281.

Njisane, Y.Z. \& Muchenje, V., 2013a. Influence of municipal abattoir conditions and animal-related factors on avoidancerelated behaviour, bleeding times at slaughter and the quality of lamb meat. Asian Austral. J. Anim. Sci. 26, 14961503.

Njisane, Y.Z. \& Muchenje, V., 2013b. Quantifying avoidance-related behaviour and bleeding times of sheep of different ages, sex and breeds slaughtered at a municipal and a commercial abattoir. S. Afr. J. Anim. Sci. 43, S38-S42.

Njisane, Y.Z., 2016. Farm to abattoir conditions and their subsequent effects on behavioural and physiological changes and the quality of beef from extensively-reared Nguni and non-descript steers. PhD Agriculture (Animal Welfare and Meat Science) thesis. University of Fort Hare, South Africa.

Probst, J.K., Neff, A.S., Hillmann, E., Kreuzer, M., Koch-Mathis, M. \& Leiber. F., 2014. Relationship between stressrelated exsanguination blood variables, vocalisation, and stressors imposed on cattle between lairage and stunning box under conventional abattoir conditions. Livest. Sci. 164, 154-158.

SAS, 2003. SAS/STAT Software Release 6.12. SAS Institute Inc., Cary, NC, USA.

Scholtz, M.M., Bester, J., Mamabolo, J.M. \& Ramsay, K.A. 2008. Results of the national cattle survey undertaken in South Africa, with emphasis on beef. Appl. Anim. Husb. Rural Dev. 1, 1-9.

Schwartzkopf-Genswein, K.S., Faucitano, L., Dadgar, S., Shand, P., González, L.A. \& Crow, T.G. 2012. Road transport of cattle, swine and poultry in North America and its impact on animal welfare, carcass and meat quality: A review. Meat Sci. 92, 227-243.

Seshoka, M. L., Kanengoni, A.T., Siebrits, F.K. \& Erlwangers, K.H., 2013. The novel use of "point of care" devices to evaluate transport duration on selected pork quality parameters. S. Afr. J. Anim. Sci. 43, S48-S53.

Shaw, F.D. \& Tume, R.K., 1992. The assessment of pre-slaughter and slaughter treatments of livestock by measurement of plasma constituents - a review of recent work. Meat Sci. 32, 311-329.

Sporer, K.R.B, Burton, J.L., Earley, B. \& Crowe, M.A., 2007. Transportation stress in young bulls alters expression of neutrophil genes important for the regulation of apoptosis, tissue remodeling, margination, and anti-bacterial function. Vet. Immunol. Immunop. 118, 19-29. 
Stewart, S.M., McGilchrist, P., Gardner, G.E. \& Pethick, D.W. 2015. Is it tough being stressed? Can plasma indicators of stress relate to lamb tenderness? In: Proceedings of the $61^{\text {st }}$ International Congress of Meat Science and Technology, Clermont Ferrand, France.

Stockman, C.A., McGilchrist, P., Collins, T., Barnes, A.L., Miller, D., Wickham, S.L., Greenwood, P.L., Café, L.M., Blache, D., Wemelsfelder, F. \& Fleming. P.A., 2012. Qualitative behavioural assessment of Angus steers during preslaughter handling and relationship with temperament and physiological responses. Appl. Anim. Behav. Sci. 142, 125-133.

Tarrant, P.V., 1990. Transportation of cattle by road. Appl. Anim. Behav. Sci. 28, 153-170 (Abstract).

Terlouw, E.M.C. \& Porcher, J., 2005. Repeated handling of pigs during rearing. I. Refusal of contact by handler and reactivity to familiar and unfamiliar humans. J. Anim. Sci. 83, 1653-1663.

Trunkfield, H.R. \& Broom, D.M., 1990. The welfare of calves during handling and transport. Appl. Anim. Behav. Sci. 28, 135-152.

Warriss, P.D., 2000. Meat Science: An Introductory Text. CAB International, Wallingford, U.K., pp. 312. 